(C2017, Elsevier. Licensed under the Creative Commons Attribution-NonCommercialNoDerivatives 4.0 International http://creativecommons.org/about/downloads 


\title{
Complex networks in advanced manufacturing systems
}

\author{
Yongfeng $\mathrm{Li}^{1,2}$, Fei Tao ${ }^{1 *}$, Ying Cheng ${ }^{1}$, Xianzhi Zhang ${ }^{3}$, A. Y. C. Nee \\ ${ }^{1}$ School of Automation Science and Electrical Engineering, Beihang University, Beijing 100191, P. R. China \\ 2 School of Mathematics and information Engineering, Taizhou University, Zhejiang Linhai 317000, China \\ ${ }^{3}$ School of Mechanical and Automotive Engineering, Kingston University London, London, UK \\ ${ }^{4}$ Department of Mechanical Engineering, National University of Singapore, Singapore \\ E-mail: ftao@buaa.edu.cn
}

\begin{abstract}
In recent years, with the rapid development of manufacturing, information, and management technology, advanced manufacturing systems (AMSs) have become increasingly more and more complex, which hinders the wider applications of many key theories and technologies in AMSs. Fortunately, in the last two decades, some dramatic advances have been made in the field of statistical physics theories, along with the extensive applications of complex network. It has provided an alternative approach to analyze AMSs. Many recent studies have focused on the theory of complex networks to describe and solve complicated manufacturing problems. Based on a great number of relevant publications, this paper presents an up-to-date literature review with the identified outstanding research issues, future trends and directions. Three critical issues are summarized after this investigation: (a) the focused areas of AMSs that have deployed the theory of complex networks, (b) the addressed issues and the corresponding approaches, and (c) the limitations and directions of the existing works.
\end{abstract}

Keywords: Advanced manufacturing systems (AMSs), Complex networks, Collaborative networks, Manufacturing service, Hyper-network

\section{Introduction}

The scientific development in the past few years indicates that the social environment for manufacturing has changed significantly, such as the growing global market competition and the diversity of customer demands. Responding to the changing environment, the manufacturing industry and related enterprises have been paying more attention to some manufacturing characteristics such as agile, networking, service-oriented, green, socialization, etc [1-3]. In order to reach the goals of TQCSEFK (i.e., fastest Time-to-market, highest Quality, lowest Cost, best Service, cleanest Environment, greatest Flexibility, and highest Knowledge), researchers have proposed a variety of advanced manufacturing systems (AMSs) and modes [4].

AMSs have been playing a vital role during the last 20 years in the manufacturing industry development. However, focusing on the modes, architectures, key technologies, and application 
platforms of different AMSs, the literatures still seem to be lack of statistical researches, especially in the field of the broader applications in manufacturing industry. Fortunately, in the last two decades, researchers have witnessed dramatic advances in the statistical physics theories of complex networks [5-7], which has provided an alternative approach to analyze the AMSs. The origin of complex network is discrete mathematics and graph. It provides a set of tools to quantitatively analyze the structural heterogeneity of networks. It has developed over decades as a theoretical framework for the understanding of the network structural characteristics. Inspired by real-world networks, a great number of interdisciplinary studies of complex networks have led to the development of many empirical network metrics. Its models apply across a wide range of research fields successfully.

Based on the search of Web of Science, Scopus, Springer Link, IEEE Xplore, Journal of Mechanical Engineering and Journal of Computer Integrated Manufacturing Systems (two journals which are the most authoritative academic journals in the field of digital and advanced manufacturing in China), 150 articles on complex networks in AMSs from 2000 to 2015 are collected and selected in this paper. The paper reviews and analyzes the literatures systematically with the aim to investigate the applications of complex networks in AMSs and then provides some references for the in-depth studies on AMSs.

The rest of this paper is organized as follows. Section 2 describes the research methodology and classifies the literatures on complex networks in AMSs. Section 3 gives the detailed reviews and discussions of the selected researches. Based on the identified limitations, the future trends and derived further works are pointed out in Section 4. Finally, Section 5 summarizes the whole paper and the contributions.

\section{Complex networks in AMSs}

In order to review the literatures systematically and clarify the research methodologies, from (1) material collection, to (2) category selection, and (3) descriptive analysis, three steps are described for the researches on complex networks in AMSs.

\subsection{Material Collection}

Material collection methodology is the first step of the literature review process. The review is based on the search among academic journals, articles and books, primarily in Scopus, Web of Science (WoS), Springer Link, IEEE Xplore, and the most authoritative two related journals in China (i.e., Journal of Mechanical Engineering, and Computer Integrated Manufacturing), ranging over the period from 2000 to 2015 (up to April 1, 2015). The review primarily focuses on the applications of complex networks in AMSs. Besides, it is carried out in three stages: (a) searching in scientific databases with relevant keywords, (b) identification of relevant papers from reading abstracts, and (c) full-text reading and grouping into specific research topics.

The main relevant manufacturing fields are manufacturing systems networks, manufacturing networks, collaborative manufacturing networks, collaborative product design networks, product networks, production/manufacturing process networks, supply chain networks, logistics networks, 
sensor networks, resource services networks, etc. Finally, 150 articles in total were selected, reviewed and examined in detail. The number of articles analyzed for the review appears to be adequate as the focus on specific issues, which is consistent with the number of articles analyzed in recent literature reviews in the area of manufacturing.

\subsection{Category selection}

The selected articles were sorted out from more than fifty journals. The corresponding annual distributions of the selected articles are shown in Fig. 1. Obviously, most of the selected articles were published in recent five years.

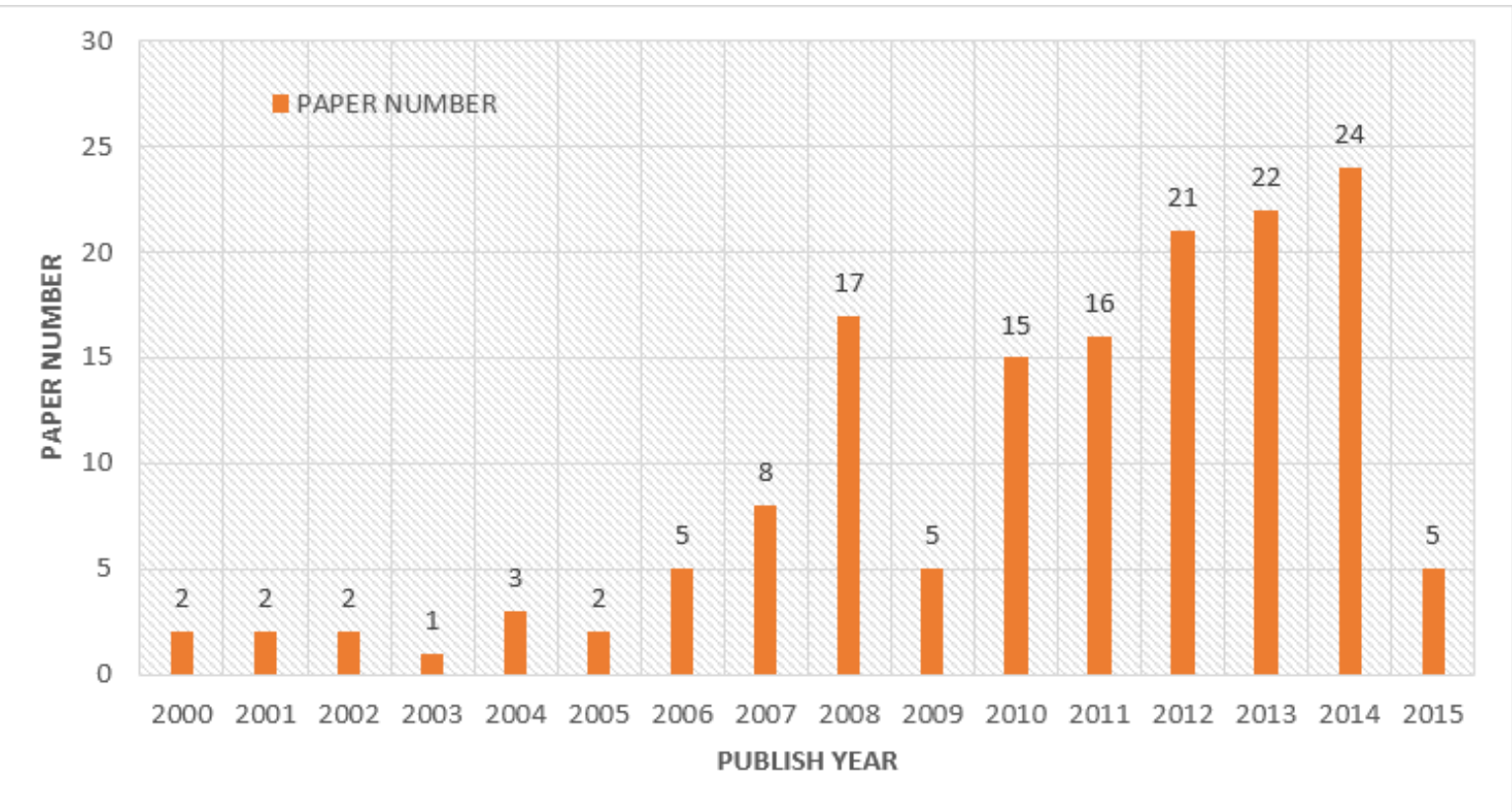

Fig. 1 Paper distribution in international journals and conferences since 2000 (up to April 1, 2015)

Regarding to the selected articles, there are various types of study subjects about complex networks in AMSs. Furthermore, considering the whole lifecycle of product, and pursuing the full cooperation and integration of labor, process and resources in a single enterprise or among multiple ones, a framework model of manufacturing system network is constructed based on introducing Internet into manufacturing [8]. As shown in Fig. 2, the framework model is classified into two categories: in enterprise and among enterprises.

1) In enterprise: It promotes the integration of production-related information, product-related information, and other business management information, and the integration of the workshop and other enterprise information subsystems, as well as the integration of the planning and controlling information in the physical manufacturing execution process from materials and semi-finished products to the final products. Enterprises can generate manufacturing resources services for the participations in the external supply chain, in addition to the management of the internal supply chain.

2) Among enterprises: It addresses the information integration, storage, retrieval, analysis, use, data security, and other issues during ubiquitous services management and application processes among 
massive different enterprises.

According to the two classified categories above, the selected articles just pay attention to some of the specific issues illustrated in the framework model of manufacturing system networks. As shown in Fig. 3, from the two categories of 'in enterprise' and 'among enterprises', the selected articles are mainly focused on the sub-categories such as product design stage and production stage, enterprise collaboration, services, supply chain, logistic networks, and organization structure, respectively.

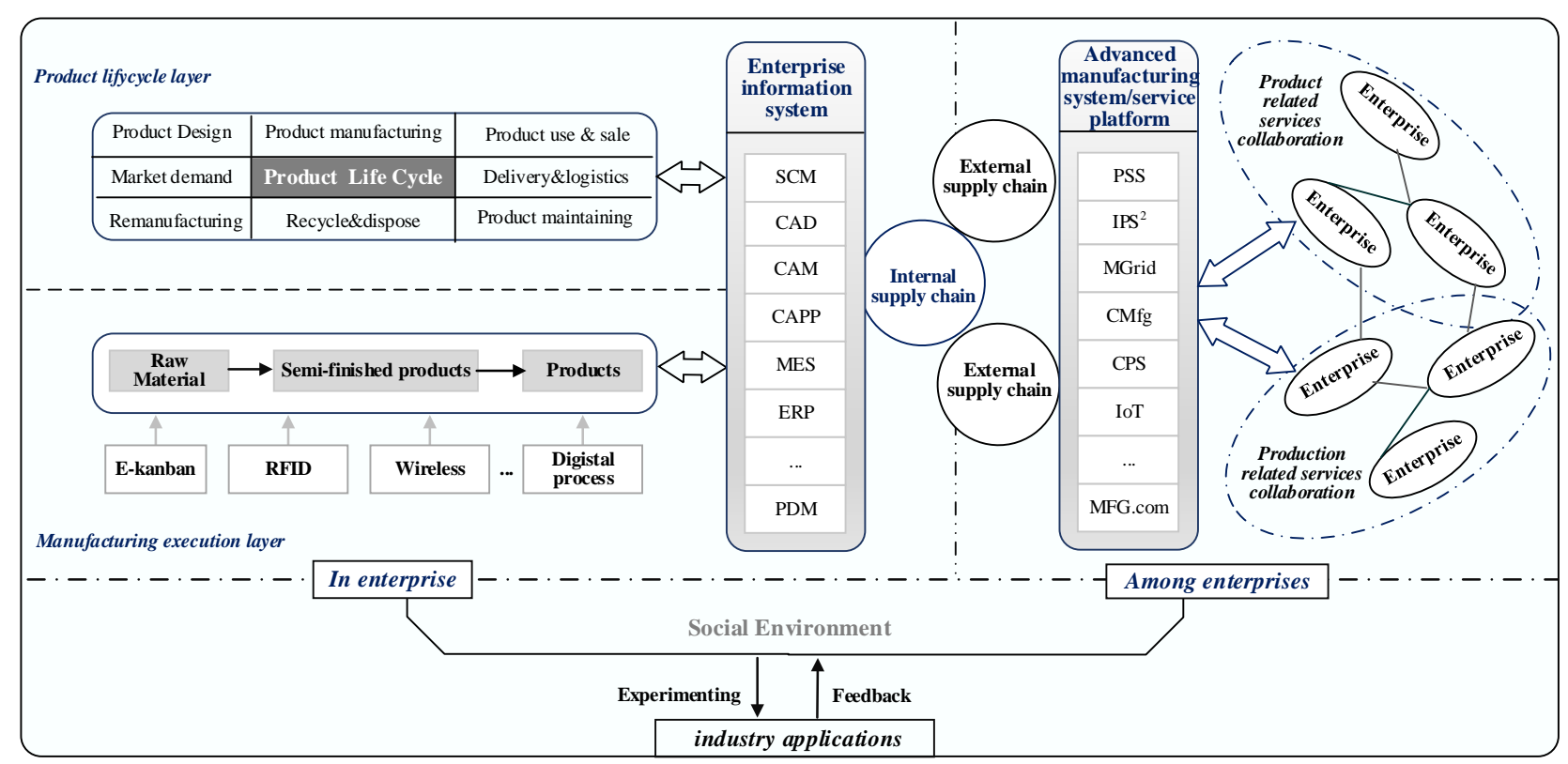

Fig. 2 The framework model of manufacturing systems network

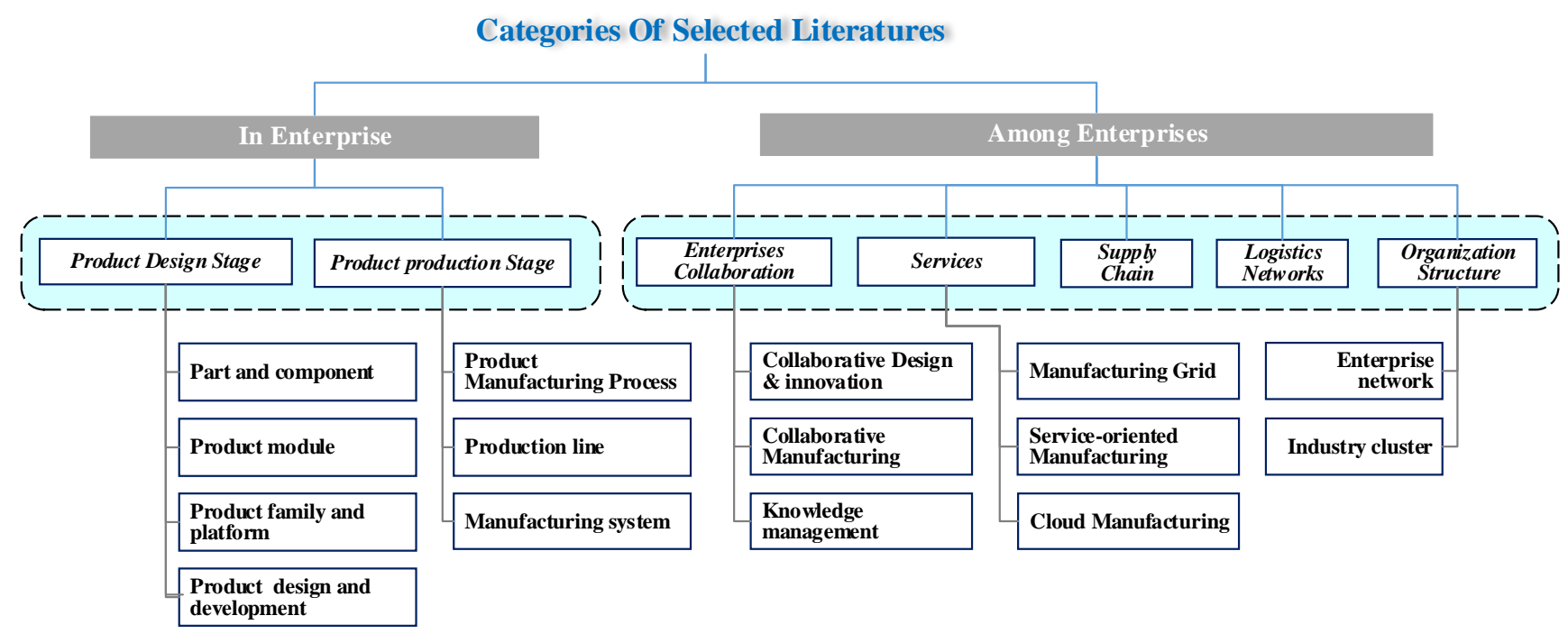

Fig. 3 Categories selection of Literature reviews

\subsection{Descriptive analysis}

For the classification of the selected articles, the distributions by categories are descriptively counted and illustrated in Fig. 4 and Table 1. As can be seen, the applications of complex networks in AMSs are mainly concentrated on the product production stage (20\%), product design stage (19.4\%), supply chain (16.7\%), enterprise collaboration (15.3\%) and service (11.3\%). In addition, for the specific issues of each sub-category, supply chain, industry application and product manufacturing process are 
the top three research topics. Known from the statistics, the existing researches on complex networks in AMSs are more than those in the empirical stage. The detailed review and discussion on each specific issue of each category will be given in section 3 .

Table 1 Detailed list of the related subject category (up to April 1, 2015)

\begin{tabular}{|c|c|c|c|}
\hline Categories & Sub-categories & Specific issues & Number of Articles \\
\hline \multirow{8}{*}{$\begin{array}{c}\text { In enterprise } \\
(39.4 \%)\end{array}$} & \multirow{5}{*}{$\begin{array}{l}\text { Product design stage } \\
\qquad(19.4 \%)\end{array}$} & Part and component & $6(4 \%)$ \\
\hline & & Product module & $10(6.7 \%)$ \\
\hline & & Product farmily \& platform & $4(2.7 \%)$ \\
\hline & & product design \& & \\
\hline & & development & $8(0 \%)$ \\
\hline & \multirow{3}{*}{$\begin{array}{l}\text { Product production stage } \\
\qquad(20 \%)\end{array}$} & Production process & $12(8 \%)$ \\
\hline & & Production line & $7(4.7 \%)$ \\
\hline & & Manufacturing systems & $11(7.3 \%)$ \\
\hline \multirow{8}{*}{$\begin{array}{l}\text { Among enterprises } \\
\qquad(60.6 \%)\end{array}$} & & Collaborative design $\&$ & \\
\hline & Enterprise Collaboration & innovation & \\
\hline & $(15.3 \%)$ & Collaoratvie production & $8(5.3 \%)$ \\
\hline & & Knowledge management & $5(3.3 \%)$ \\
\hline & Service $(11.3 \%)$ & & $17(11.3 \%)$ \\
\hline & Supply chain(16.7\%) & & $25(16.7 \%)$ \\
\hline & Logistics networks(7.3\%) & & $11(7.3 \%)$ \\
\hline & Organization structure(10\%) & & $15(10 \%)$ \\
\hline
\end{tabular}

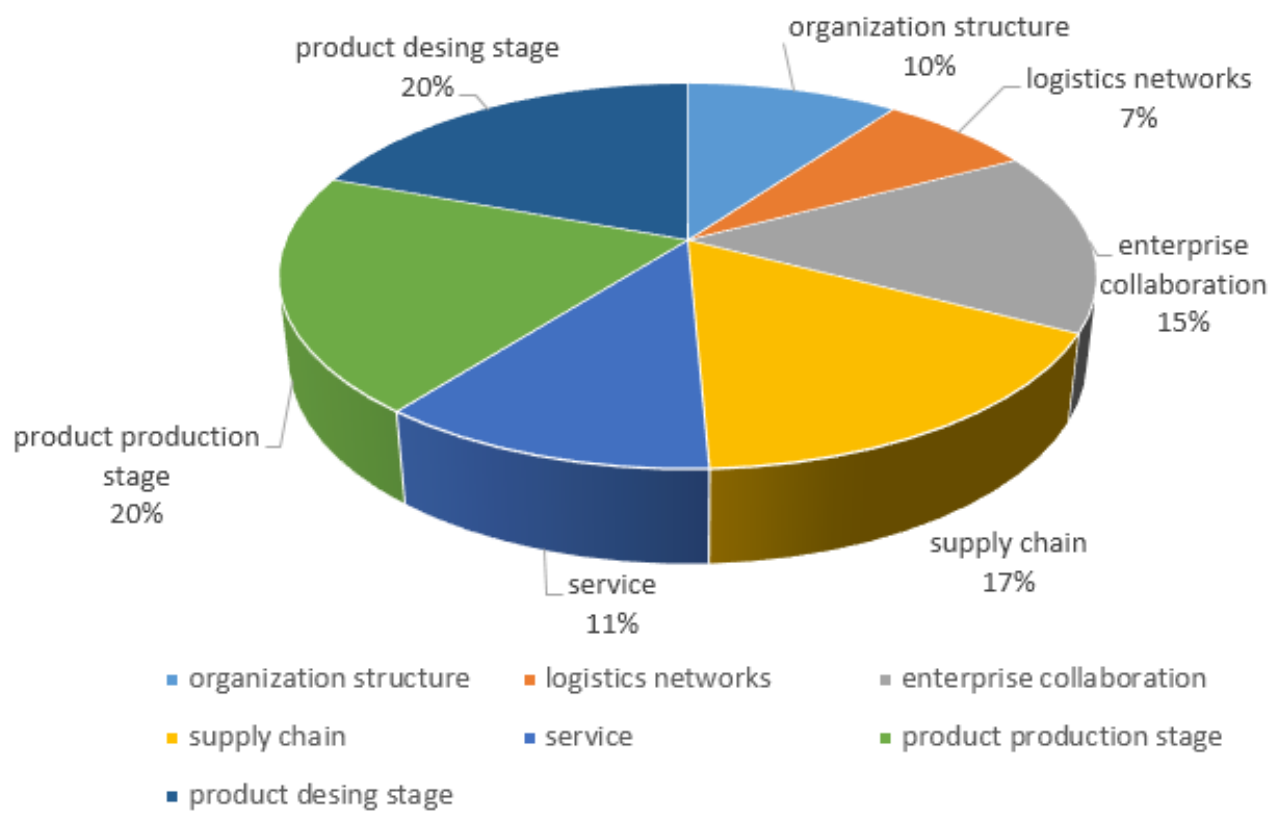

Fig. 4 Distribution of the related subject in these papers (up to April 1, 2015) 
Based on the above categories and the specific issues, two questions can be answered in this section.. It includes: (1) what applications of complex network are put forward in AMSs, and (2) what problems they have carried out.

\subsection{In enterprise}

The literatures on complex networks applications in enterprise are mainly divided into product design stage and product production stage.

\subsubsection{Product design stage}

Product design stage mainly refers to the stage before product manufacturing in an enterprise. Based on the selected literatures, it includes part and component, product module, product family and product design and development. The complex network theory is used to reveal the complicated relations between product composition and assembly, as well as the information and knowledge flow.

\subsubsection{Part and component}

Complex products are comprised of many parts with intricate relationships, and those relationships can be described by the theory of complex networks. Introducing network topology to mass customization, the weighted directed complex networks with parts are regarded as vertexes, and the relations between them are considered as edges. The in-degree distribution and out-degree distribution of the parts relation network satisfy a power law, which is called scale-free characteristic [9-11]. For example, some new parameters, such as generalized in-degree, generalized out-degree and generalized connection, are introduced to obtain more accurate results [12]. In order to study the parts relation network of product family deeply, detection of simple paths in the parts relation network is investigated. Based on the parts relation network, forecasting the number of parts and components is also studied to optimize inventory management and production planning [13]. Simultaneously, the evolving rule of parts relation network is also carried out [14].

Finding: There are 4\% of selected papers (6 papers) [9-14] on the topic of parts and components, among which 6 papers are on the topological models of parts relation network and the characteristics, and 2 papers are on the dynamic behavior. These works are mainly used to verify the characteristics of small-world and scale-free networks of component relationships in product family or not by empirical and simulation study. Though the evolution laws of components are researched, the network models are generated by catching hold of the growing and preferential mechanisms of BA (Barabási-Albert, BA) model, which depicts the evolution process of scale-free network based on the growing and preferential attachment mechanisms. It needs to consider much more factors to obtain more accurate evolution models with the relationships between parts and components.

\subsubsection{Product module}

Product modularity is one of the most important characteristics in product family. In addition, module partition and configuration is the core of product modularity. Some works are on the construction of modular relation network and product configuration based on parts relation network. 
For module partition, a large commercial aircraft engine is used as an example to test the impact of modularity on component redesign by a network approach with the analysis of degree distribution, average path length and connection [15]. Results show that the relationship between component modularity and component redesign depends on the interface type of product components connection. The components relation network model is introduced and built for product family structure [16]. In order to evaluate the product modularization, a part relation network of product family is constructed. Moreover, a simple-path detecting algorithm is studied for product module division by Fan et al. [17]. As to the module partition problem of complex products and systems, a modified Girvan-Newman (GN) algorithm is adopted to establish this module partition problem [18]. To judge module partition, another work is developed to calculate the modularization coefficient and the modularization grade of complex products [19].

For product configuration, a transfer method for correlative coefficient computing is put forward by applying directed network to represent product family structure [20]. They also studied dimension parameter transfer [21], modification and variant design method [22] of product configuration. Furthermore, to realize the variant design of assembly containing standard component, the parameters of assembly are analyzed s [23], and a note on minimum makespan assembly plans is modeled by utilizing directed hyper graphs [24].

Finding: In total, $6.7 \%$ of selected papers (10 papers) [15-24] are on this topic. It is obvious that product module partition gets much more attention compared to product configuration. The existing works on product configuration still focus on the configuration method and system implementation. These researches mainly focus on the characteristics and evolution laws of component relation network on one hand, and on the other hand analyze selection, parameters modification and variant design of the configure module and product modularization evaluation. They provide new method and tool for product modularity related researches. However, more sophisticated mathematical models and analysis methods are required to evaluate module partition entirely and effectively.

\subsubsection{Product family}

The structure of product family is an effective measure to implement mass customization production [25]. The product family is made up of products with similar functions, structures or technologies. A product family structure model employing complex networks is constructed at first [16]. In order to describe the relationship among constituent components of product family structure, the network model is proposed to utilize edges representing the parent-child relations and functional relationship of components. A simple path-detecting algorithm is used to obtain the statistical characteristics of constituent components of the product family. By analyzing the module conjunction characteristics of the constructed network, the results can be used to guide the evolution process of product family structure [26]. By applying the structure network of product family, a structural rationalization method of product family is presented [27]. Moreover, Liu et al. present a structure-based product platform by 
combining complex network theory with axiomatic information [28].

Finding: The characteristics and evolution rules of component network model and component class network model are preconditions for the researches on the network model of product family structure and its platform. Hence, some related works have been described in the previous two topics, ignoring these literatures, only 4 papers (2.7\% of selected papers) [25-28]discuss about product family structure, and are with greater value by combining complex networks to existing product design methods. However, the further researches are required to collect more data from real general products so that the network model of product family structure could be improved.

\subsubsection{Product design and development}

Product development process can be generally divided into five major phases: concept development, system-level design, detail design, testing and refinement, and production ramp-up [29]. Each phase is decomposed into a large number of design activities. The design activities create an enormous, complex, and unstructured network. Some network-based researches have been put forward. For example, the network structure and the statistical mechanics are applied to the dynamics of large-scale product development [30-32]. Fu et al. point out the modeling and performance analysis of product development process networks [33]. Hultin et al. propose a model of network-of-networks to manage the complexity of product development [34]. Due to the tight connections among complex products, the dynamic behaviors are also important. As a result, the engineering changes [35-36], variant design, and the design processes streamlining [37] based on complex product development networks are carried out.

Finding: There are 6\% of selected papers (9 papers) [29-37] on this topic. The complex product structure and many design activities make the network topology of product development process more obvious but complex, especially the network topology with the dynamic behaviors in the product design and development process. These works mainly consisted of two main layers. One is engineer changes in product design process, and the other is structure changes in product design process. In order to create cost-efficient project plans and ultimately design solutions quickly, engineering changes are determined by the quantitative measurement for product development process network. More physics characteristics should be defined to reflect real situations of engineering changes in product development process network. As for the product structure changes, it still lacks further investigations on the core dynamics by analyzing the information flow between nodes and knowledge developments within them. Therefore, the dynamics methodology and the Network-of-Networks with uncertainty can be paid attention in the future.

\subsubsection{Product manufacturing stage}

For product manufacturing stage, the process is mainly considered from raw material to production stage in enterprise. Based on the selected and classified literatures, it is mainly concerned with product fabrication processes and manufacturing systems, the relations exploration of workstations, and the monitoring of equipment and production line with both material and information flow. 


\subsubsection{Production process}

Product manufacturing process includes processes from raw material, semi-products to final products. It makes a difference to the overall production process with the current diversification and specialization tendencies, which results in irregular and unpredictable dynamics of production processes. Actually, it consists of multistage machining processes (MMPs) in production processes. Due to the complicated interactions between the different machining form features and machining status, the production process is dynamic and its error propagation path is complex. Therefore, the theory of complex networks also has some advantages on the analysis of MMPs. A weighted network is introduced, and the variation propagation stability of MMPs is analyzed by the virus spreading model based on complex networks [38-39]. Similarly, complex networks are introduced to describe these interactions and the error propagation in MMPs [40-42].

Regarding the quality attributes of work pieces and their processing elements (i.e., machine tool, cutting tool and fixture, etc.) as different nodes, a machining error propagation network (MEPN) is established with graph theory, and then the shortest path length, clustering coefficient and degree of distributions of MEPN are discussed in detail. The results show that once a quality defect of these nodes occurred, the machining quality of work pieces would not be stable. Then the dynamic MEPN is defined [43-45]. The dynamic model of MEPN provides a real-time and dynamic quality control method. A system framework and a weighted-coupled network-based dynamic quality control method are proposed to improve the machining errors of one key feature in production process [46-47]. In order to monitoring and estimating the status of quality features, a general approach for quality monitoring and diagnosing in MMPs utilizing Bayesian networks is presented [48]. Furthermore, a quality control fractal network is established for extended enterprises by considering the constraint relationship among nodes [49].

Finding: In the 12 papers on this topic ( $8 \%$ of the selected papers) [38-49], the network models of multistage machining processes are proposed by combining the real network characteristics with complex networks theory. The variation propagation and quality control for multistage machining processes based on a number of measurement indicators are analyzed. However, there still are some problems. For example, the measurement indicators are constantly changing, the real-time status of each equipment in production process is different, and so on. The models of multistage machining processes network need to be improved by collecting more accurate data, considering more factors, and designing more sophisticated optimization algorithm.

\subsubsection{Production line}

Production line is a complex system because of the complicated manufacturing process, multiple types, high machining difficulty and many special processes in it. So complex networks are also a very good tool to deal with the complicated relationships in production line. The research team in Northwest Polytechnic University in China introduces the small-world and weighted complex networks to build 
and analyze the production line network [50]. The results show that complex network is a feasible method to deal with the complicated problems in production line. Based on the production line network model, service capacity [51-54], reliability and balance [55], robust and vulnerability [56] of production line are studied, respectively.

Finding : 7 papers (4.7\% of selected papers) [50-56] are classified into this topic. Some achievements are on the optimization problems for reliability evaluation of production line. Due to the great difficulty of collecting other companies' data, the above researches on production line are just for specific target company. As a result, the following issues should be carried out in the next further discussions: (1) consider more process-related factors (e.g., process time, process cost, process route, etc.) to improve production line network model, (2) try to optimize the capacity, balance and reliability of production line underlying the network model, (3) analyze the dynamics in deep and design more excellent optimization algorithms for production line network model, etc.

\subsubsection{Manufacturing system}

A traditional manufacturing system is composed of a number of elements, workstations, machines, buffers, transportation devices, and so on. It integrates the materials, information, and financial flows between above elements [57]. Investigating the topology of manufacturing systems as complex networks of material flow is an approach, which is put forward recently [58]. After the network for manufacturing systems being built, it is proved with the scale-free and small-world characteristics, and with no high clustering coefficient [59]. For the general work systems, a method of discovering autonomous structures in complex networks is presented specific to the material flow in shop floor. It also proposes an analysis method of anomalies detection with the theory of complex networks [60-61]. Besides the corresponding network modeling, an investigation on the performance and viability of centralized and decentralized production networks is presented [62], and it is used to exploit the availability of large-scale data sets in manufacturing by applying measures from complex network theory and classical performance evaluation. With regard to more advanced topological measures, a model using complex network figures is designed to improve heuristics for manufacturing system design [63]. As to the stability and reliability of manufacturing systems, robustness evaluation and measures, characterization and classification [64], as well as cascading failures on dynamic models of complex manufacturing network [65] are analyzed respectively. In order to evaluate a manufacturing system and its dynamic behaviors, a network motif is applied as a similarity indicator to assess the similarity and dissimilarity of manufacturing systems [57]. Moreover, a new approach is introduced to solve the tool-switching problem arising in flexible manufacturing systems [66], and a graph-theoretic, linear-time scheme to detect and resolve deadlocks in flexible manufacturing cells is utilized [67].

Finding: Known from the above 11 papers (7.3\% of selected papers) [57-67] on this topic, these researches are mainly to create a manufacturing systems network model to address the following three 
issues: (1) how to model a manufacturing system as a network, (2) what dynamic behaviors in such a network are measured, and (3) how to detect and assess these behaviors. It shows that the network modeling of manufacturing systems is feasible and is particularly helpful for analysis of large manufacturing systems. However, the researches on evolution law and performance evaluation for manufacturing systems are still not enough.

\subsection{Among enterprises}

Different from the applications of complex networks in enterprise, the literatures on the applications of complex networks among enterprises primarily include the collaboration and cooperation between manufacturing enterprises in the whole product lifecycle or in industry cluster.

\subsubsection{Enterprises collaboration}

\subsubsection{Collaborative design and innovation}

Recently, with the rapid development of information technology, the collaborative work in a product design process has been widely used in industrial areas, which improves product design quality, shortens design time and enhances customer satisfaction [68]. With the globalization of industry, the collaborative design process becomes a complex system in which design activities and various elements (e.g. design activities, interdisciplinary knowledge, experts from different areas, and so on) are involved.

In order to analyze the performance of complex systems for supporting design process organization, operation, control and management, the collaborative design process has been abstracted as a network named collaborative design network (CDN) [69]. Zhang et al. propose a new concept of scale-free collaborative product designing resource network to describe the features of the distributed design resources and to support the utilization and sharing of design resources by calculating and analyzing their dynamic characteristics based on the scale-free theory and model [70]. By introducing the network community and using network analysis techniques, the properties of collaborative design community are designed and discussed [71].

Driven by the collaborative product design, customer collaborative product innovation (CCPI) and corresponding collaborative networks attract more attention as a new model [72]. Furthermore, they study the essentiality model for customer churn and its ripple effects [73], importance evaluation method for innovative customer [74], the robustness and optimization method [75], the system stability and centrality analysis in CCPI system [76-77].

Finding: According to the classification and description, there are 10 papers (6.7\% of selected papers) [68-77] on this topic. It takes customer knowledge and creativity as the most valuable innovation sources in collaborative product design. The works in the section are to construct the network model for the product distribution, product design and innovation, and to analyze the network topology and dynamic behaviors. Due to the lack of empirical research from real world, further researches need to be done in the following issues: (1) how to improve the network model considering more factors, (2) how 
to utilize propagate, control and graph theory of complex networks to the whole process of product design and innovation, (3) how to study the relationship of product-customer-knowledge in the networks by using the community network and hyper-network, and so on.

\subsubsection{Collaborative production}

The collaborative manufacturing network is an alliance of business entities (mostly manufacturers and suppliers) among which the relations are extremely complex that collaborate on the production of complex products [78-79]. From the perspective of global structure, the complex network theory which reveals the hidden laws of collaborative manufacturing network could solve the complex and even international collaborative production. Firstly, the topological model for inter-firm collaborative production networks $(\mathrm{CPN})$ is developed with the analysis of the characteristics of inter-firm collaborative production [80]. Furthermore, correlation analysis of failure modes and vulnerability in CPN is studied based on the undirected weighted networks [81-83]. Aiming at collaborative mode for business-related multi-industrial chain, a mathematical model is established for the proposed collaborative network, and it shows that the business-related multi-industrial chain network node strengthens the distribution following the power-law distribution [84]. Moreover, a risk spread model of the industrial chain, which is applied and verified on the collaborative network of an automobile part industrial chain, is established [85].

Finding: There are 8 papers (5.3\% of selected papers) [78-85] on collaborative production. However, the works almost focus on the undirected models of collaborative production network, and it is not adequate for the weighted network. Considering dynamic environment, it is necessary to pay much attention to the vulnerability and risk assessments of collaborative production because of the lack of control and feedback in production processes.

\subsubsection{Knowledge system}

The knowledge system is a complex adaptive system consisting of knowledge, related activities and other components. A knowledge system within a firm, involves different functions and members, and it is a typical complicated network with a variety of stakeholders. Hence, the complex networks theory can also be adopted in related research of knowledge system. For example, a knowledge resource cooperation complex networks for regional manufacturing is proposed to analyze the innovation ability of an organization and help distribute knowledge resources to business processes [86]. In order to decrease the complexity and uncertainty of knowledge management, the complex network is introduced into the knowledge management of manufacturing enterprises [87]. The correlation of knowledge is analyzed based on complex network for the knowledge integration [88]. Liu and Liao propose a method of knowledge evaluation and correlation analysis to acquire and reuse manufacturing knowledge and to improve the efficiency of decision-making based on complex networks [89]. Finally, Yang et al. built a complex networks model of design knowledge according to the application features of design knowledge in the innovative solution-seeking process and the many-to-many mapping relationships 
among three levels of knowledge [90].

Finding: In total, 5 papers (3.3\% of selected papers) [86-90] are carried out on this topic. They illustrate the link relationships between knowledge and business for enterprises organizational structure, product manufacturing, collaborative design and innovation, as well as the allocation relationships between knowledge and resources by using the theory of complex network. However, the network models of knowledge systems should be further considered with knowledge semantics, domain ontology, and other factors.

\subsubsection{Services}

Under the environment and trend of servitization in manufacturing [4], service requires intelligent management with much more collaboration and cooperation. Thus, manufacturing grid (MGrid), service-oriented manufacturing (SOM), cloud manufacturing (CMfg) and other AMSs are presented successively. There are also some applications of complex networks into these systems because of their complexity.

For example, in MGrid systems, Liu et al. carry out a complex network model of production-collaboration, illustrate the average path length based flexibility analysis, and put forward the network evolution and resource allocation considering economics, robustness, and other external factors [91-92]. In order to resolve the difficulty to trace the order sheets and extract the manufacturing process in mass customization, a manufacturing network model in MGrid based on complex network theories is interconnected and interlaced by task assignment network, completion feedback network and information communication network [93]. As for the resource nodes in MGrid systems, the degree of nodes, the shortest path between each two nodes, the synchronization performance, and community partition are discussed, respectively [94-96]. Besides, the degree distribution, the mode dole, the average path length and the clustering coefficient are also analyzed in another work [97].

In SOM systems, the workable resource pool is described considering small world network characteristic [98]. Compared to the enterprise collaboration network in SOM [80], a service-oriented manufacturing network based on the complex weighted network theory is defined. Furthermore, the statistic parameters, the conception of product service network and product service chain, the microcosmic constitution of product service systems, and the coupling mechanism between services are studied [99]. For the concept of social manufacturing which is extended from SOM, the enterprise relationship network based on social network is modeled and analyzed [100-101].

In CMfg systems, a correlation-aware service combination network with the scale-free dynamics is proved theoretically, and dynamic evolution operators of service combining network are designed and studied firstly [102].An evolution model of CMfg and its evolution mechanism is proposed and investigated in the following researches. It is found that there exists an intermediate task saturation degree resulting the most extensive participation in CMfg [103]. To analyze and evaluate virtual enterprise venture, a trust network structure pattern mining based on CMfg platform is presented which 
includes the ontology representation, static and dynamic modeling and the push and pull service mechanism [104]. In addition, a hyper graph clustering-based cloud manufacturing service management method is presented by $\mathrm{Wu}$ et al. [105]. Similar to SOM systems, a social network analysis approach is formulated to analyze the socio-technical network generated by cloud-based design and manufacturing (CBDM) systems. The results indicate that social network analysis allows for visualizing collaborative relationship patterns of actors as well as detecting the community structure of CBDM systems [106].

Finding: After introducing the thought of service-oriented architecture (SoA) into AMSs, the modes and systems of MGrid, SOM, CMfg and other AMSs with the concept of "manufacturing services" are getting more and more attentions. Thus there are almost 17 papers (11.3\% of selected papers) [91-107] on this topic. These papers mostly research on the relationship of resource nodes using complex network theory, and analysis of network topological models, critical statistical indicators, robustness, information spread and community structure, in order to reveal the inner law of network models and to select, composite and allocate manufacturing resource or service nodes with the optimal decision-making. Due to the servitization and socialization of manufacturing, more and more researches are addressing the complex networks based supply-demand matching of manufacturing services and enterprises collaboration with the characteristic of socialization, uncertainty and dynamics [107].

\subsubsection{Supply chain}

A supply chain can be defined as a network of autonomous or semiautonomous business entities collectively responsible for procurement, manufacturing and distribution activities associated with one or more product families. Different entities in a supply chain operate subjects to satisfy different sets of constraints and objectives [108]. In recent years, many researchers and practitioners have established supply chain networks in manufacturing to describe and analyze the whole performance of the supply chain with complex networks.

From the view of network model, supply chain networks prove to be small world networks [109-110]. Wang discusses the directed network system of supply chain networks for the product family [111]. A whole directed supply chain network model is developed by Wen et al. on the basis of complex network theory and its statistic characteristics have been analyzed [112-114]. Xuan et al. propose a new framework of the model, analyze the topological structure of supply networks, and illuminate which of the three different supplier-customer connecting rules might lead to better performance of supply chain networks [115]. Based on complex network theory and two-phase methodology, Zheng and Liang consider the dynamics in the design of complex supply chain network [116].

As for the reliability research, Sun and Wu analyze the robustness of supply networks created by their own scale-free model [117]. In order to facilitate the decision-making process, Vafa et al. use social network analysis tool to establish a visualization supply chain networks model [118]. The importance of nodes in supply chain network is analyzed using the theory and methods of complex network [119]. Moreover, the obtained results have been applied to supply chain network of automobile industry in 
Guangzhou to demonstrate its key nodes. Wen et al. list different manifestations of the proposed complex supply chain network, especially the robustness of the network [108]. The source of the supply chain risk is revealed by Yi et al. through a complex supply chain network modeling evolution. The ability of the supply chain network to resist risks can be improved largely by working closely with key nodes and increasing network resilience [120].

From the view of improving methods, Wu et al. present a novel matrix-based Bayesian approach for the optimal resource selection in supply chain of manufacturing resources [121]. A new entropy approach is developed by Zeng et al. to study the vulnerability of cluster supply chain network during the cascading failure spreading from a holistic point of view [122]. The tools of complex network theory and social network analysis are used to obtain the network representation of cluster supply chain system and explain its cascading phenomenon. By defining critical routes, Safaei et al. calculate the delivery time uncertainty of a stochastic and mathematical model in supply networks [123]. This approach can be used as a tool for managers to control and monitor the uncertainty in complex networks. Qin et al. discuss various uncertainties of supply chain networks in manufacturing industry, and analyze the spread and control of uncertainty of complex supply chain network in manufacturing industry [124]. These researches show that enterprises could be capable of coping with uncertainty effectively by reducing delivery lead times and strengthening the exchange of information. Kim et al. advance a more precise definition of supply chain networks disruption which benefits from a deeper understanding of supply network structure and its influences on disruption risk and resilience at the network-level [125]. Kaihara and Fujii propose an economic negotiation mechanism with a complex network for supply chain management [126]. In order to promote the modularization of member enterprises, a supply chain network for the product family is proposed by Wang [111]. An agent-based network analysis is applied to the evolution of complex adaptive supply chain networks [127]. Furthermore, the multi-agent systems and the interactions between them have been represented [128-130]. From the view of complex supply networks, the survivability and robustness are also explored. In order to improve the flexibility of supply chain, hyper-network is used to study integrated E-supply chain networks [131-132].

Finding: For the massive researches on supply chain network, 25 papers (16.7\% of selected papers) [108-132] have been analyzed and discussed. It is clear that supply chain is a popular research topic. The researches on supply chain network cover not only the product plan, purchasing, inventory, diversity, the relationship of suppliers, distributors and retailers, but also the complete manufacturing process. The existing works mainly focus on the construction of supply network models and the analysis of its dynamical behaviors and characteristics, especially on uncertainty and vulnerability analysis, robustness and cascading failure, risk assessment. In future works, combining supply networks with logistics networks, product design networks, product development networks, product manufacturing networks, social networks and multi-agent networks may be the challenges.

\subsubsection{Logistics networks}


Logistics systems are required to operate efficiently in order to reduce the use of resources and time. In recent years, logistics systems have led to a wide range of research activities in production logistics and supply chain management as part of the just-in-time philosophy and inventory optimization strategies [133]. It is claimed that logistics network is a complex dynamical system and the optimization and control of the networks are hot research topics [134].

Most researchers devote to discussing the network models and characteristics to solve some logistics management problems. Deng and Chen study the logistics network model and its characteristics of growth, preferential attachment, edge-weighted and clustering [135]. A small-world network based information flow network model and its sharing mechanism are presented and analyzed [136-137]. The information shared in one maintenance logistics system is provided to illustrate the feasibility of the proposed method. Using the theory of complex networks, Chen et al. propose a scale-free network model of the growth of logistics information networks [138]. Scholz-Reiter et al. investigate the problem of model reduction with a view of large-scale logistics networks [139]. Yao et al. study the behavior dynamics for the large-scale logistics system warehouse-out operation systematically [140]. $\mathrm{Zu}$ et al. study the complex regional logistics network and its evolutionary mechanism [141]. The green logistic network in an eco-industrial system is designed by modifying the BA model based on the intrinsic properties of eco-industrial systems [142]. Meepetchdee and Shah characterize the logistical networks by using graph theoretic formalisms to observe average path length, clustering coefficients and degree distributions, propose a conceptual framework for designing logistical networks with desired levels of robustness, and explore relationships of logistical network efficiency, robustness, and complexity through mathematical models [143].

Finding: From the above 11 papers (7.3\% of selected papers) [133-143], it can be seen that the researches on logistics network gradually expand to the completely manufacturing process. However, how to identify other aspects of robustness and complexity, how to solve the scientific problems about dynamics fuzziness, randomness, and nonlinearity in regional logistics network organization, still need to be paid much more attention.

\subsubsection{Organization structure}

The organization of virtual enterprises and their alliance is with complex network topology. The complex and dynamic enterprise network is of diverse internal connection, which eventually leads to the complexity of the entire network system [5]. A manageable small world community for collaborative enterprises within virtual organization is proposed, and the experimental results show that the small-world community network is highly clustered, short in diameter, easy to manage, and highly scalable [144]. Then the social network analysis is used as a tool to improve the architectures of enterprises and their alliance. [145]. Furthermore, a deterministic hierarchical network model is proposed, and its statistical properties in manufacturing are discussed. The simulation results prove that the artificial networks can simultaneously possess small-world and scale-free properties well [146]. 
In addition, it is drawing more and more attention by researchers, from enterprises alliance to industry clusters. By introducing complex network theories into industrial clusters, it can also generate much useful insight for industry organization analysis from the macro aspect. Known from the selected literatures, it also has the specific applications based on complex networks in different industries. For example, automotive industry [146-148], aircraft and aerospace industry [149-150], electronics and semiconductor industry [151-152], home appliance manufacturing industry [153], shipping manufacturing [154], ceramic industry [155] and others [156-158]. These results are helpful for the decision support for enterprises and governments both in micro level and in macro level to respond to the dynamic competitions.

Finding: In total, there are 15 papers (10\% of selected papers) [144-158] on organization structure. It is helpful for the architecture improvement of enterprises, alliances and industry clusters. However, it lacks the real-life data of manufacturing enterprises, and it is important to improve the enterprise networks or to optimize measurements indices with the real-life data. In addition, the competition assessment for industry cluster, statistical analysis and evolution of the networks of different industry clusters are the most important issues in the future researches.

\section{Trends and future works}

In section 3, it summarizes and analyzes the selected literatures on the applications of complex networks in AMSs by category. In this section, it will answer the third question mentioned in the abstract, expounding what are the limitations and directions of the existing works.

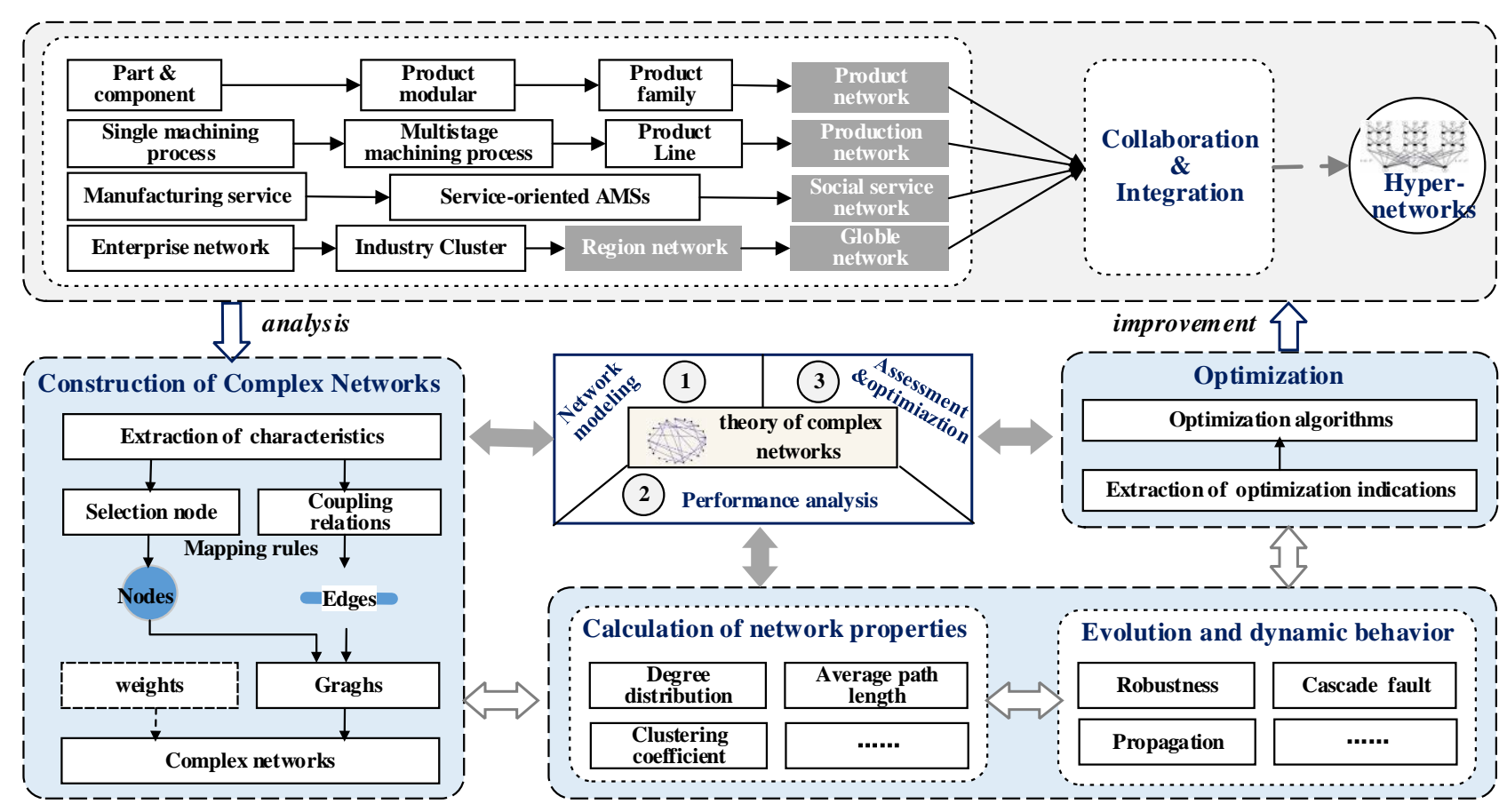

Fig. 5 The work principle of network theory and the whole development sequence in AMSs

Based on the previous discussion on the different categories of researches, the comprehensive analysis from a holistic view is pointed out and divided into the following four aspects: product-related, 
production-related, service-related, and enterprise-related researches. The whole development sequence of the applications of complex networks in AMSs is constructed as showed in Fig. 5.

Product-related research takes product design as the main line to integrate the related researches in the levels of both in one enterprise and among multiple enterprises. It includes the product design and the collaborative design innovation in this category. From the view of analyzed literatures, researches on component and product family sprung up from 2005 to 2010. Product module related researches emerged between 2007 and 2014. In addition, researches on collaborative product design and development mainly appeared between 2012 and 2015. As known from the above discussion, the researches of this category experience several stages as follows, the relationship of parts and components, the product module, the product family, and finally the product networks.

Production-related research takes production as the focus to integrate the related works both in and among enterprises. The production stage and the collaborative production are included in this category. From this respect, the researches of this category develop from different stages, including single process stage, multistage machining process, production line, shop floor layout, and production networks and even production hyper-network.

In service-related researches, the service is taken as the focus to integrate the researches about manufacturing resource services in an enterprise and among different enterprises. It includes enterprise structure, industry cluster and its application with the consideration of manufacturing services. Summarized from the selected literatures, the related research involves manufacturing servitization and service-oriented manufacturing, and evolves to service network, service chain network, and service hyper-network.

Enterprise-related research takes organization as the core to integrate the related researches of manufacturing enterprise organization structure in different manufacturing industries. From this perspective, the researches of this category develop as it is going through single enterprise, enterprises network, industry cluster, region network, and global network.

Based on the analysis of the whole development sequence of the applications of complex networks in AMSs, complex network theory is the effective means and tendency of product-related, production-related, service-related, and enterprise-related researches. There exist various problems of networks intertwined and network of networks in complex systems, although complex networks can model and analyze diversified network structure. Specially, hyper-networks can be used to describe and represent the interaction and influence between networks. In addition, the collaboration and integration of multi-layer networks between product-related, production-related, service-related, and enterprise-related networks can be realized through hyper-networks. Currently, the applications of complex networks in AMSs mostly focus on exploration and verification phase, such as constructing a network topology structure, analyzing the statistical characteristics, making manufacturing plan and 
formulating the macro control, and so on. Some research works are still not in depth, such as microscopic analysis, the feedback mechanisms of manufacturing process, the dynamic characteristics, and collaboration between processes. Some future works are inspired by the researches, such as (1) try to find more appropriate network models for AMSs and make the network model more close to real world, (2) try to find the measurement indices to understand the dynamic characteristics and behaviors of networks, (3) try to design the advanced optimal algorithms in order to get feasible and optimal solutions for desired objectives in AMSs.

\section{Conclusions}

In the last two decades, it has shown an increasing interest in network science applied into manufacturing. The present article provides a survey of the available literature on the applications of complex networks in AMSs with a special emphasis on framework model of manufacturing system networks based on the papers from 2000 to 2015. The framework model is classified into two categories of in enterprise and among enterprises. It has also been found that there is a rapid growth in the number of papers in recent five years.

From a holistic view, the whole development sequence on the applications of complex networks in four aspects of product-related, production-related, service-related, and enterprise-related researches is constructed. Theory of complex networks is the tendency to be studied and applied to solve complicated manufacturing problems in each aspect. Specially, hyper-network has been applied on the reviewed literature and to represent the interaction and influence between networks in four aspects. However, a deeper research is urgent in building appropriate and accurate network models such as considering more factors, realistic data, optimal algorithm and dynamic activities.

In conclusion, there are many promising research opportunities for understanding AMSs through the theory and applications of complex networks, which is undoubtedly fertile field for researches.

\section{Acknowledgements}

This work is supported in part by NSFC project (No.51522501 and No. 51475032), Beijing Nova Program and Beijing Natural Science Foundation (4152032).

\section{References}

[1] Kastalli IV, Van Looy B. Servitization: disentangling the impact of service business model innovation on manufacturing firm performance. Journal of Operations Management 2013; 31(4):169-180.

[2] Rusinko CA. Green manufacturing: an evaluation of environmentally sustainable manufacturing practices and their impact on competitive outcomes. IEEE Transactions on Engineering Management 2007; 54(3):445-454.

[3] Cousins PD, Handfield RB, Lawson B, Petersen KJ. Creating supply chain relational capital: the impact of formal and informal socialization processes. Journal of Operations Management 2006; 24(6):851-863. 
[4] Tao F, Cheng Y, Zhang L, Nee AYC. Advanced manufacturing systems: socialization characteristics and trends. Journal of Intelligent Manufacturing 2015; DOI: 10.1007/s10845-015-1042-8. .

[5] Strogatz SH. Exploring complex networks Nature 2001; 410(6825):268-276.

[6] Albert R, Barabási AL. Statistical mechanics of complex networks. Reviews of Modern Physics 2002; 74(1):47-97.

[7] Newman MEJ. The structure and function of complex networks. SIAM Review 2003; 45(2):167-256.

[8] Tao F, Cheng Y, Xu LD, Zhang L, Li BH. CCIoT-CMfg: Cloud computing and internet of things-based cloud manufacturing service system. IEEE Transactions on Industrial Informatics 2014; 10(2):1435-1442.

[9] Liu FY, Qi GN. Application in manufacturing industry: a complex network method. Shanghai Scientific \&Technological Education Publishing House, 2006.

[10]Liu FY and Qi GN. Research on component relation network of product family and its application. International Journal of Materials and Product Technology 2008; 31(2-4):186-201.

[11] Sui RB, Zhong GJ. Research on degree distribution of networks of parts relationship for product family on scale-free networks. In: 2008 International Conference on Wireless Communications, Networking and Mobile Computing; 2008. p. 1-4.

[12]Xi Z, Zheng XJ. Evolution law for the complex network of mass customization in the machine manufacturing. In: Proceedings of the 2009 6th International Conference on Service Systems and Service Management; 2009. p. 516-521.

[13]Liu FY, Qi GN, Yang QH. Forecast method for used number of parts and components based on complex network. Chinese journal of Mechanical engineering 2006; 42(6):1-6.

[14]Liu FY. Research on evolving rule of parts relation network for product family. 3rd International Conference on Semantics, Knowledge, and Grid; 2007. p. 582-583.

[15] Sosa ME, Eppinger SD, Rowles CM. A network approach to define modularity of components in complex products. Journal of Mechanical Design, Transactions of the ASME 2007; 129(11):1118-1129.

[16]Fan BB, Qi GN. Modeling of product family structure and module analysis method based on complex network. Chinese Journal of Mechanical Engineering 2007; 43(3):187-192.

[17]Fan BB. Modularization analysis approach of product family for DFMC based on complex network. Advanced Materials Research 2013; 712-715:2970-2978.

[18]Newman MEJ, Girvan M. Finding and Evaluating Community Structure in Networks. Physical Review E 2004; 69(2):1-15.

[19]Liu FY, Qi GN. Research on Evaluation Method of Modularization Grade of Products. Journal of China Mechanical Engineering 2008; 19(8):919-924.

[20]Liu FY, Qi GN. Correlative coefficient computing method of configuration module. Computer 
Integrated Manufacturing Systems 2007; 13(1):18-23.

[21] Liu FY, Qi GN. Dimension parameters transfer method of configuration product and its application. Chinese Journal of Mechanical Engineering 2007; 43(4):144-151.

[22]Liu FY, Deng XL. Dimension parameter modification and variant design method of configuration product. Computer Integrated Manufacturing Systems 2008; 14(11):2092-2096.

[23] Xu K, Liu FY, Li G. Research on assembly variant design based on complex network. Advanced Materials Research 2011; 201-203:189-193.

[24] Gallo G, Grazia Scutellà M. A note on minimum makespan assembly plans. European Journal of Operational Research 2002; 142(2):309-320.

[25] Tseng MM, Jiao JX. Fundamental issues regarding developing product family architecture for mass customization. Integrated Manufacturing Systems 1988; 11(7):469-483.

[26] Xu X, Gao L, Fang S. Product family architecture evolution based on technology evolution theory of TRIZ. In: Proceedings of the World Congress on Intelligent Control and Automation (WCICA); 2008. p.5662-5666.

[27]Liu F, Song S, Kuang B. Research on structure rationalization method of product family and its application. Advanced Materials Research 2010; 97-101:3443-3446.

[28]Liu X, Qi G, Ji Y, Gu X, Xu X. Product platform design method based on complex network and axiomatic design. Chinese Journal of Mechanical Engineering 2012; 48(11):86-93.

[29] Ulrich KT, Eppinger SD. Product Design and Development. New York: McGraw-Hill; 1995.

[30]Braha D, Bar-Yam Y. The Structure and Dynamics of Complex Product Design. Understanding Complex Systems; 2006. P. 40-71.

[31]Braha D, Bar-Yam Y. The statistical mechanics of complex product development: Empirical and analytical results. Management Science 2007; 53(7):1127-1145.

[32]Jun HB, Suh HW. A modeling framework for product development process considering its characteristics. IEEE Transactions on Engineering Management 2008; 55(1):103-119.

[33]Fu LJ, Jiang PY, Cao W. Modeling and performance analysis of product development process network. Journal of Network and Computer Applications 2013; 36(6):1489-1502.

[34]Hultin A, Tryfonas T, Johnston N, Kirkman M. Modelling effective product development systems as network-of-networks. In: 8th Annual IEEE International Systems Conference; 2014. p. 89-96.

[35] Li JB, Zhang DH, Li S. Engineering change management based on weighted complex networks. In: Proceedings-2008 International Seminar on Future Information Technology and Management Engineering; 2008. p. 304-308.

[36] Cheng H, Chu XN. A network-based assessment approach for change impacts on complex product. Journal of Intelligent Manufacturing 2012; 23(4):1419-1431.

[37]Cheng H, Chu XN. Product design process management system based on design stream line. Computer Integrated Manufacturing Systems 2012; 18(12):2579-2587. 
[38] Qin YT, Zhao LP, Yao YY. Dynamic quality characteristics modeling based on brittleness theory in complex manufacturing processes. International Journal of Computer Integrated Manufacturing 2011; 24(10):915-926.

[39] Qin YT, Zhao LP, Yao YY. Multistage machining processes variation propagation analysis based on machining processes weighted network performance. International Journal of Advanced Manufacturing Technology 2012; 55(5-8):487-499.

[40]Liu D, Jiang P. Modeling of machining error propagation network for multistage machining processes. Lecture Notes in Computer Science (including subseries Lecture Notes in Artificial Intelligence and Lecture Notes in Bioinformatics) 2008; 5315 LNAI (PART 2):408-418.

[41]Liu D, Jiang P. The complexity analysis of a machining error propagation network and its application. Proceedings of the Institution of Mechanical Engineers, Part B: Journal of Engineering Manufacture 2009; 223(6):623-640.

[42]Liu DY, Jiang PY. Fluctuation analysis of process flow based on error propagation network. Chinese Journal of Mechnical Engineering 2010; 46(2):14-21.

[43]Jia F, Jiang PY, Liu DY. Error propagation control method for multistage batches machining processes of blades. Computer Integrated Manufacturing Systems 2012; 18(1):76-86.

[44] Jiang PY, Wang Y, Wang HF, Zheng M. Quality Prediction of Multistage Machining Processes Based on Assigned Error Propagation Network. Chinese Journal of mechanical Engineering 2013; 49(6):160-170.

[45] Jiang P, Jia F, Wang Y, Zheng M. Real-time quality monitoring and predicting model based on error propagation networks for multistage machining processes. Journal of Intelligent Manufacturing 2014; 25(3):521-538.

[46]Diao GZ, Zhao LP, Yao YY. A system framework of dynamic coupled quality control based on complex network. Advanced Materials Research 2013; 711:773-778.

[47]Diao G, Zhao L, Yao Y. A weighted-coupled network-based quality control method for improving key features in product manufacturing process. Journal of Intelligent Manufacturing 2016; 27(3):535-548.

[48] Wolbrecht E, Ambrosio BD, Paasch B, Kirby D. Monitoring and diagnosis of a multi-stage manufacturing process using Bayesian networks. Artificial Intelligence for Engineering Design, Analysis and Manufacturing 2000; 14(1):53-67.

[49]Qin Y, Zhao L, Yao Y, Xu D. A quality control model for extended enterprises and its implementation. IFIP Advances in Information and Communication Technology 2008; 254(1):185-194.

[50] Yang T, Zhang D, Chen B, Li S. The small-world network model of mixed production line. Intelligent Robotics and Applications Lecture Notes in Computer Science 2010; 6425(6):22-31.

[51] Yang T, Zhang D, Chen B, Li S. Analysis of Mixed Production Line Based on Complex Weighted 
Network. In: 2010 International Conference on Intelligent Computation Technology and Automation; 2010. P. 667-670.

[52] Yang T, Zhang D, Chen B, Li S. Research on service capacity of production line based on complex weighted network. In: 2010 International Conference on Management and Service Science; 2010. p.1-4.

[53] Yang T, Zhang D, Chen B, Li S. Capacity planning for mixed production line based on directed weighted networks. Journal of China Mechanical Engineering 2011; 22(7):824-829.

[54] Yang T, Zhang D, Chen B, Li S. Non-cooperative Game Decision for Capacity Evaluation under Output Demand Uncertainty. In: IEEE International Conference on Industrial Engineering and Engineering Management; 2011. p. 560-564.

[55] Yang S, Li S, Chen B, Yang T. Stability analysis of mixed production lines based on process routes optimization. Computer Integrated Manufacturing Systems 2013; 19(10):2424-2431.

[56]Li YP, Chu XN, Chu DX, Liu QM. An integrated module partition approach for complex products and systems based on weighted complex networks. International Journal of Production Research 2014; 52(15):4608-4622.

[57] Beber ME, Becker T. Towards an understanding of the relation between topological characteristics and dynamic behavior in manufacturing networks. Procedia CIRP 2014; 19:21-26.

[58] Nyhuis P, Wiendahl H. Fundamentals of Production Logistics: Theory, Tools and Applications. Springer Science\&Business Media; 2008.

[59]Liu FY, Deng XL. Research on manufacturing network and its statistic characteristics. Electro-Mechanical Engineering 2008; 24(1):11-13.

[60] Vrabič R, Husejnagić D, Butala P. Discovering autonomous structures within complex networks of work systems. CIRP Annals-Manufacturing Technology 2012; 61(1):423- 426.

[61] Vrabič R, Škulj G, Butala P. Anomaly detection in shop floor material flow: A network theory approach. CIRP Annals-Manufacturing Technology 2013; 62(1):487-490.

[62] Mourtzis D, Doukas M, Psarommatis F. A multi-criteria evaluation of centralized and decentralized production networks in a highly customer-driven environment. CIRP Annals-Manufacturing Technology 2012; 61(1):427-430.

[63] Blunck H, Vican V, Becker T, Windt K. Improvement heuristics for manufacturing system design using complex network figures. Procedia CIRP 2014; 17:50-55.

[64]Becker T, Meyer M, Windt K. A manufacturing systems network model for the evaluation of complex manufacturing systems. International Journal of Productivity and Performance Managemen 2014; 63(3):324-340.

[65]Zhan G, Qingbo Z, Tingxin S. Analysis and research on dynamic models of complex manufacturing network cascading failures. In: 2014 6th International Conference on Intelligent Human-Machine Systems and Cybernetics; 2014. P. 388-391. 
[66]Djellab H, Djellab K, Gourgand M. A new heuristic based on a hypergraph representation for the tool switching problem. International Journal of Production Economics 2000; 64(1):165-176.

[67] Venkatesh S, Smith JS. A graph-theoretic, linear-time scheme to detect and resolve deadlocks in flexible manufacturing cells. Journal of Manufacturing Systems 2003; 22(3):220-238.

[68] Weiming S, Qi H, Li WD. Computer supported collaborative design: Restropective and perspective. Computer in Industry 2008; 59(9):855-862.

[69]Fu LJ, Jiang PY, Zhu QQ. Performance Analysis of Collaborative Design Network. In: Proceedings of the 2012 IEEE 16th International Conference on Computer Supported Cooperative Work in Design; 2012. p. 393-397.

[70]Zhang HF, Gu XJ, Qi GN. Study on scale-free product collaborative design supporting platform. In: Proceedings of the IEEE International Conference on Industrial Technology; 2008. p. 1-5.

[71]Fuge M, Tee K, Agogino A, Maton N. Analysis of collaborative design networks: A case study of openideo. Journal of Computing and Information Science in Engineering 2014; 14(2):021009.

[72]Danowski JA. Identifying collaborative innovation networks: At the inter-departmental level. Procedia - Social and Behavioral Sciences 2010; 2(4):6404-6417.

[73] Yu GD, Yang Y, Tan WJ. Modeling for essentiality of innovative customer in CCPI with customer $\begin{array}{lllll}\text { churn } & \text { and } & \text { its } & \text { ripple }\end{array}$ http://www.cnki.net/kcms/detail/11.3619.TP.20141024.1633.008.html.

[74]Li F, Yang Y, Xie JZ, Zhang F. Importance evaluation method for innovative customer in collaborative products innovation. Computer Integrated Manufacturing Systems 2014; 20(3):537-543.

[75] Yu GD, Yang Y, Li F. Analysis and optimization on robustness of customer collaborative product innovation systems. Computer Integrated Manufacturing Systems 2014; 20(12):2926-2934.

[76] Li F, Yang Y, Xie J. Network centrality analysis in customer collaborative product innovation design process. International Journal of Applied Mathematics and Statistics 2013; 43(13):357-367.

[77]Li F, Yang Y, Xie J, Liu A, Chen Q. Selection method of customer partners in customer collaborative product innovation. Journal of Intelligent Systems 2014; 23(4):423-435.

[78] D’Atri A, Motro A. Virtue: a formal model of virtual enterprises for information markets. Journal of Intelligent Information Systems 2008; 30(1):33-53.

[79] Guo Y, Motro A. Autonomy in collaborative manufacturing networks. In: Proceedings of the 10th IEEE International Conference on Collaborative Computing: Networking, Applications and Worksharing ;2015. p. 253-260.

[80]Zhang FQ, Jiang PY, Zhu QZ, Cao W. Modeling and analyzing of an enterprise collaboration network supported by service-oriented manufacturing. Proceedings of the Institution of Mechanical Engineers, Part B: Journal of Engineering Manufacture 2012; 226(9):1579-1593.

[81]Zhang F, Yang Y, Jia JG. Vulnerability analysis of collaborative production networks based on 
undirected weighted graph. Journal of Chinese Mechanical Engineering 2012; 23(10):1216-1220.

[82]Zhang F, Yang Y, Bao BF. System vulnerability analysis of collaborative production networked organizations. Computer Integrated Manufacturing Systems 2012; 18(5):1077-1086.

[83]Zhang F, Yang Y, Jia JG. Correlation analysis of failure modes and vulnerability in collaborative production networked organizations. Computer Integrated Manufacturing Systems 2012; 18(6):1236-1245.

[84] Chen J, Sun LF. Model of business-related multi-industrial chain collaborative network. Computer Integrated Manufacturing System 2010; 16(5):1088-1095.

[85]Chu YF, Dai MM. Research on risk spread model of industrial chain. Grey Systems: Theory and Application 2014; 4(2):328-338.

[86]Zhan HF. Research on building method of knowledge resource cooperation complex network for regional manufacturing. Advanced Materials Research 2010; 37-38:985-989.

[87]Zhang HF, Yang JJ, Yu FH. Design of knowledge resource allocation system for manufacturing enterprises. Advanced Materials Research 2011; 338:777-781.

[88]Liu JJ, Liao WH, Guo Y. Knowledge integration model for networked manufacturing. Advanced Materials Research 2011; 314-316:2027-2032.

[89]Liu JJ, Liao WH, Guo Y. Knowledge evaluation and correlation analysis for proliferating manufacturing based on complex network. Computer Integrated Manufacturing Systems 2012; 18(10):2204-2210.

[90] Yang k, Li Y, Xiong Y. Research on knowledge driven product innovative design based on complex network. Computer Integrated Manufacturing $\quad$ Systems http://www.cims-journal.cn/CN/abstract/abstract4902.shtml.

[91]Liu LL, Sun XH, Shu ZS, Tian S, Yu T. A production-collaboration model for manufacturing grid. Lecture Notes in Computer Science 2010; 6328 LNCS (PART 1):166-175.

[92]Liu LL, Sun XH, Hu XP, Cai HX. Resource allocation and network evolution considering economics and robustness in manufacturing grid. Journal of Advanced Manufacturing Technology 2011; 57(1):393-410.

[93] Yan P, Wang D, Chen G, Liu F, Zhao J. A production schedule obtaining method based on information spreading relationship network in manufacturing process. China Mechanical Engineering 2010; 21(9):1046-1052.

[94] Yin Y, Li Y, Lin W, Hua E. Directed-weighted modeling of resource node in manufacturing grid and its application analysis. Advanced Materials Research 2012; 472-475:2626-2631.

[95] Yin Y, Zhang CY, Chen DJ. Complex network based modeling \& analysis of resource nodes for MG. Applied Mechanics and Materials 2014; 619:332-336.

[96] Yin Y, Li Y, Zhang CY. Study on community structures in manufacturing grid and the algorithm for community partition of its resource nodes. Applied Mechanics and Materials 2014; 526:222-229. 
[97] Hu FH, You H. The selection of manufacturing grid resources node based on the model. Advanced Materials Research 2014; 926:842-845.

[98] Xu XW, Gang D, Tan J. Research for technology in distributed manufacturing with resource collaboration. Advanced Materials Research 2013; 753-755:1875-1881.

[99]Li J, Mo R, Sun HB. Product service system evaluation based on complex network. Computer Integrated Manufacturing Systems 2013; 19 (9):2355-2363.

[100] Leng J, Jiang P, Zhang F, Cao W. Framework and key enabling technologies for social manufacturing. Applied Mechanics and Materials 2013; 312:498-501.

[101] Ding K, Jiang PY, Leng JW, Cao W. Modeling and analyzing of an enterprise relationship network in the context of social manufacturing. Proceedings of the Institution of Mechanical Engineers, Part B: Journal of Engineering Manufacture 2015; doi: 10.1177/0954405414558730.

[102] Tao F, Guo H, Zhang L, Cheng Y. Modelling of combinable relationship-based composition service network and the theoretical proof of its scale-free characteristics. Enterprise Information Systems 2011; 6(4):373-404.

[103] Liu Y, Zhang L, Tao F, Wang L. Development and implementation of cloud manufacturing: An evolutionary perspective. In: ASME 2013 International Manufacturing Science and Engineering Conference Collocated with the 41st North American Manufacturing Research Conference; 2013.

[104] Pan T, Zheng L. Trust network modeling for Virtual Enterprise Cloud manufacturing. International Journal of Digital Content Technology and its Applications 2012; 6(5):115-123.

[105] Wu L, He M, Han Y. Hypergraph clustering-based cloud manufacturing service management method. In: Proceedings of the 2014 IEEE 18th International Conference on Computer Supported Cooperative Work in Design; 2014. p. 220-225.

[106] Wu D, Schaefer D, Rosen DW. Cloud-based design and manufacturing systems: A social network analysis. In: Proceedings of the International Conference on Engineering Design; 2013. P. 149-158.

[107] Cheng Y, Tao F, Xu LD, Zhao DM. Advanced manufacturing systems: supply-demand matching of manufacturing resource based on complex networks and Internet of things. Enterprise Information Systems 2015; DOI: 10.1080/17517575.2016.1183263.

[108] Wen L, Guo M, Wang L. Statistic characteristics analysis of directed supply chain complex network. International Journal of Advancements in Computing Technology 2012; 4(21):84-91.

[109] Hearnshaw EJS, Wilson MMJ. A complex network approach to supply chain network theory. International Journal of Operations and Production Management 2013; 33(3-4):442-469.

[110] Zhao D. The research of supply chain modeling based on the improved complex network theory. In: 2009 International Conference on Artificial Intelligence and Computational Intelligence; 2009. P. 172-175.

[111] Wang ZH. Study on the supply chain system for the product family based on the complex 
network. In: 2010 2nd International Conference on E-Business and Information System Security; 2010. p.1-4.

[112] Wen L, Guo M, Wang L. The directed complex network application in the supply chain. In: 2012 3rd International Conference on Digital Manufacturing and Automation; 2012. p. 911-914.

[113] Wen L, Xu L, Wang L. Research on the robustness of the complex supply chain network. In: 2012 3rd International Conference on Digital Manufacturing and Automation; 2012. p. 719-722.

[114] Wen L, Xu L, Wang L. Research on the robustness of the directed complex supply chain network. Journal of Information and Computational Science 2013; 10(2):563-570.

[115] Xuan Q, Du F, Li Y, Wu TJ. A framework to model the topological structure of supply networks. IEEE Transactions on Automation Science and Engineering 2011; 8(2):442-446.

[116] Zheng JB, Liang Y. A dynamic model for the design of complex supply chain network. In: 2010 International Conference on Computer Application and System Modeling; 2010. p. V15-472-V15-475.

[117] Sun H, Wu J. Scale-free characteristics of supply chain distribution networks. Modern Physics Letters B 2005; 19(17):841-848.

[118] Vafa MA, Hong TS, Yusuff RM, Ibrahim R, Mamdooh M. Developing theoretical framework for visualizing the supply chain using social network analysis. In: 38th International Conference on Computers and Industrial Engineering; 2008. P. 1142-1151.

[119] Zhang X, Han J. Analysis on the importance of nodes in supply chain network. In: Proceedings of the 2011 International Conference on Business Computing and Global Informatization; 2011. p.387-388.

[120] Yi CQ, Meng SD, Zhang DM. Studies on the supply chain risk management using complex network. In: Proceedings of 2nd International Conference on Logistics, Informatics and Service Science; 2012. p. 181-187.

[121] Wu J, Zhang WY, Zhang S, Liu YN, Meng XH. A matrix-based Bayesian approach for manufacturing resource allocation planning in supply chain management. International Journal of Production Research 2013; 51(5):1451-1463.

[122] Zeng Y, Xiao R. Modelling of cluster supply network with cascading failure spread and its vulnerability analysis. International Journal of Production Research 2014; 52(23):6938-6953.

[123] Safaei M, Mehrsai A, Thoben KD. A computational method in analyzing of delivery time uncertainty for highly complex supply networks. Measurement: Journal of the International Measurement Confederation 2014; 55:549-563.

[124] Qin XH, Luo BN, Gong JQ. Uncertainty spread and control of complex supply chain networks in manufacturing industry. Advanced Materials Research 2013; 712-715:3161-3164.

[125] Kim Y, Chen YS, Linderman K. Supply network disruption and resilience: A network structural perspective. Journal of Operations Management 2015; 33-34:43-59. 
[126] Kaihara T, Fujii N. A proposal of economic negotiation mechanism with a complex network for supply chain management. Procedia CIRP 2013; 12:318-323.

[127] Ponnambalam L, Tan A, Fu X, Yin XF, Wang Z, Goh RSM. An agent-based network analytic perspective on the evolution of complex adaptive supply chain networks. In: 2013 3rd International Conference on Instrumentation Control and Automation (ICA); 2013. p. 68-73.

[128] Wu L. Research on multi-agent simulation of supply network from the perspective of holistic network. In: 2011 4th International Conference on Information Management, Innovation Management and Industrial Engineering; 2011. p. 423-426.

[129] Hari P T, Usha N R, Soundar K, Réka A. Survivability of multiagent-based supply networks: a Topological Perspective. IEEE Intelligent Systems 2004; 19(5):24-31.

[130] Ponnambalam L, Long DH, Sarawgi D, Fu X, Mong Goh RS. Multi-agent models to study the robustness and resilience of complex. In: Supply Chain Networks Proceedings of 2014 International Conference on Intelligent Autonomous Agents, Networks and Systems; 2015. p.7-12.

[131] Luo Y, Zhou M, Caudill RJ. An Integrated e-supply chain model for agile and environmentally conscious manufacturing. IEEE/ASME Transactions on Mechatronics 2001; 6(4):377-386.

[132] Dotoli M, Fanti MP, Meloni C, Zhou MC. Design and optimization of integrated e-supply chain for agile and environmentally conscious manufacturing. IEEE Transactions on Systems, Man, and Cybernetics Part A: Systems and Humans 2006; 36(1):62-75.

[133] Chankov SM, Becker T, Windt K. Towards definition of synchronization in logistics systems. Procedia CIRP 2014; 17:594-599.

[134] Peters K, Seidel T, Lämmer S, Helbing D. Logistics networks: Coping with nonlinearity and complexity. Understanding Complex Systems; 2008. P. 119-136.

[135] Deng J, Chen G. Research on logistics modeling method based on complex network theories. Applied Mechanics and Materials 2011; 58-60:1210-1213.

[136] Xu Y, Qiu J, Liu G. Autonomic logistics information sharing analysis based on small-world networks. In: 2011 Prognostics and System Health Management Conference; 2011. p.1-6.

[137] $\mathrm{Wu} \mathrm{Y,} \mathrm{Ma} \mathrm{H.} \mathrm{Logistics} \mathrm{network} \mathrm{nodes} \mathrm{importance} \mathrm{analysis} \mathrm{based} \mathrm{on} \mathrm{the} \mathrm{complex} \mathrm{network}$ theory. Applied Mechanics and Materials 2013; 336:2410-2414.

[138] Chen X, Ge M. A scale-free evolution model of logistics information networks. In: Proceedings of the 2nd International Conference on Transportation Engineering; 2009. p. 1299-1304.

[139] Scholz-Reiter B, Wirth F, Dashkovskiy S, Schönlein M, Kosmykov M. Structure-preserving model reduction of large-scale logistics networks: Applications for supply chains. European Physical Journal B 2011; 84(4):501-520.

[140] Yao CZ, Lin JN, Liu XF, Zheng XZ. Dynamic features analysis for the large-scale logistics system warehouse-out operation. Physica A: Statistical Mechanics and its Applications 2014; 
415:31-42.

[141] Zu QH, Wang H, Gao HY, Wu T. Research on the complex regional logistics network and its evolution mechanism. In: 2009 1st IEEE Symposium on Web Society; 2009. p.189-193.

[142] Xiao Z, Zhou G, Wang B. Using modified Barabási and Albert model to study the complex logistic network in eco-industrial systems. International Journal of Production Economics 2012; 140(1):295-304.

[143] Meepetchdee Y, Shah N. Logistical network design with robustness and complexity considerations. International Journal of Physical Distribution and Logistics Management 2007; 37(3):201-222.

[144] Liu SH, Ma YL, Mao TL. A manageable small world for collaborative enterprises social network. In: 12th IEEE International Conference on Commerce and Enterprise Computing; 2010. P. 40-47.

[145] Przemysław K, Radosław M, Sebastian P. Social network analysis as a tool for improving enterprise architecture. Springer Berlin Heigelberg 2011; 6682(1):651-660.

[146] Li JM, Zhang N. Analysis to competition network topological structure of automotive components enterprises in china. In: International Conference on Complex Systems and Applications; 2007. p. 72-79.

[147] Mamata P. Impact of the changing facets of inter-firm interactions on manufacturing excellence: A social network perspective of the Indian automotive industry. Asian Journal of Technology Innovation 2008; 16(1):117-141.

[148] Van V, Banie GB, Andre J. The importance of innovation for firm performance in the automotive component. Portland International Center for Management of Engineering and Technology 2010; 5602024:2607-261.

[149] Esposito E. Strategic alliances and internationalisation in the aircraft manufacturing industry. Technological Forecasting and Social Change 2004; 71(5):443-468.

[150] Lucio B, Pier PA. Hunting scale-free properties in R\&D collaboration networks: self-organization, power-law and policy issues in the European aerospace research area. Technological Forecasting \& Social Change 2014; 94:21-43.

[151] Ernst D. Global production networks and upgrading perspectives in East Asia's electronics industry. In: 3rd International Conference on Management of Innovation and Technology; 2002. p.12-14.

[152] Zhang X, Huang Q. Analysis of interaction structure among multiple functional process variables for process control in semiconductor manufacturing. IEEE Transactions on Semiconductor Manufacturing 2010; 23(2):263-272.

[153] Sun MM, Gao GR. The empirical study of Shandong's home appliance manufacturing industrial cluster based on complex networks. In: 2011 International Conference on E-Business and 
E-Governmen; 2011. p.1-4.

[154] Zhang A, Ren G, Jia B. Fault diagnosis for marine engine system based on complex network cluster method. Advanced Materials Research 2013; 655-657:801-805.

[155] Yang JM, Huang XZ, Zhuang D, Zhang ST. The complex network analysis of competitive relationships between manufacturers in Foshan ceramic industry cluster. In: Proceedings of 2006 International Conference on Management Science and Engineering; 2006. p. 1020-1023.

[156] Antonelli D, Caroleo B. An integrated methodology for the analysis of collaboration in industry networks. Journal of Intelligent Manufacturing 2012; 23(6):2443-2450.

[157] Xiao ZD, Hu H, Zhou GH. Study on the formation mechanism of ecological relationship in an Eco-production network based on the node correlation. In:2013 IEEE International Symposium on Assembly and Manufacturing; 2013. p. 32-36.

[158] Tang DH, Chen BK, Gao YC, Wang BH. Scale-free phenomenon in industries in China. Physica A: Statistical Mechanics and its Applications 2013; 392(23):5914-5919. 